Cuadernos de Trabajo Social

ISSN: 0214-0314

\title{
Tensiones y soportes en el proceso de formación académica de los estudiantes de Trabajo Social en una universidad pública del suroccidente colombiano
}

\author{
Mary Hellen Burbano Cerón'; Bianca Alejandra Manco Lozano²; Stefany Bastidas Rivera ${ }^{3}$
}

\begin{abstract}
Resumen. Este artículo presenta los resultados de un estudio cualitativo cuyo propósito fue comprender los momentos del proceso de formación académica que han generado mayores tensiones en los/las estudiantes de un programa académico de Trabajo Social en una universidad pública de la ciudad de Cali, en el suroccidente colombiano. Asimismo, se identificaron los principales soportes utilizados por los/as estudiantes para permanecer en el programa académico. Como resultado se encontró que durante el proceso académico formativo -entendido como una prueba estructural (Martuccelli, 2006)- los momentos más tensos fueron: el ingreso y la adaptación a la universidad, el curso de algunas asignaturas y la práctica académica. Frente a estas tensiones los y las estudiantes universitarias/os apelaron al uso de soportes de carácter interno o individual y también externos, principalmente de carácter institucional, tales como: el apoyo derivado del vínculo entre pares - compañeros de estudio- y la relación con los y las docentes de la institución. Los resultados del estudio sugieren la importancia de incluir estrategias que fortalezcan estos vínculos en los programas de permanencia universitaria.
\end{abstract}

Palabras clave: permanencia estudiantil universitaria, formación académica, Trabajo Social, tensiones y soportes.

Sumario: Introducción. 1. Aspectos teórico-metodológicos del estudio. 1.1. El punto de partida: la revisión de estudios en torno al tema. 1.2 La prueba y los soportes, conceptos clave para acceder a la experiencia de los individuos. $1.3 \mathrm{El}$ proceso de formación universitario como prueba y los soportes usados para la permanencia estudiantil. 1.4 Momentos de tensión en la formación académica de Trabajo Social. 1.5 Los soportes utilizados por los/las estudiantes en el proceso de formación académica. 1.6 Soportes institucionales. 2. Conclusiones. 3. Referencias bibliográficas.

Cómo citar: Burbano Cerón, M. H.; Manco Lozano, B. A.; Bastidas Rivera, S. (2021) Tensiones y soportes en el proceso de formación académica de los estudiantes de Trabajo Social en una universidad pública del suroccidente colombiano. Cuadernos de Trabajo Social, 34(2), 431-443.

\section{Introducción}

La permanencia estudiantil resulta de especial interés para las instituciones educativas que, a través del uso de estrategias institucionales, buscan reducir la deserción y promover la persistencia individual en los/las jóvenes para alcanzar su título profesional. Si bien ambos aspectos contribuyen a la permanencia, la mayoría de los estudios que sirvieron como antecedentes a esta investigación señalan como ha- llazgos clave aspectos individuales asociados a la personalidad o centrados en las habilidades de los/las estudiantes. Por el contrario, este estudio hace énfasis en el papel que juegan soportes externos, algunos de ellos relacionados con el apoyo derivado del vínculo entre pares, docentes, familia y pareja, la mayoría situados por fuera de estrategias intencionales que generan integración y cohesión social.

A diferencia de otros estudios que abordan la permanencia universitaria de manera cuanti-

\footnotetext{
Universidad del Valle; Colombia

E-mail: mary.burbano@correounivalle.edu.co

2 Universidad del Valle; Colombia.

E-mail: bianca.manco@correounivalle.edu.co

3 Universidad del Valle; Colombia.

E-mail: stefany.bastidas.rivera@correounivalle.edu.co
} 
tativa, esta investigación se acercó al fenómeno desde las experiencias de los/las estudiantes, recuperando a partir de sus trayectorias situaciones o momentos del proceso formativo que vivenciaron como "tensionantes" o amenazantes para su continuidad en el programa. De allí la importancia de acompañar institucionalmente a los/las jóvenes universitarios especialmente en dos de estos momentos que marcan transiciones importantes en su vida y les exigieron cambios y adaptaciones para mantenerse en el sistema educativo.

\section{Aspectos teórico-metodológicos del estudio}

Este es un estudio exploratorio y descriptivo de carácter cualitativo que permitió conocer los momentos del proceso de formación universitario que generaron mayores tensiones en los/las estudiantes del programa académico de Trabajo Social de la Universidad del Valle, así como identificar los soportes utilizados para enfrentar estos momentos y continuar su proceso formativo. Para ello se tomó una muestra aleatoria de catorce estudiantes activos/as, que correspondió aproximadamente al 32\% del total de matriculados/as en el décimo semestre, cuyas edades oscilaron entre los veintiuno y los ventitrés años. Se aplicaron entrevistas semiestructuradas a seis de ellos/ellas y una sesión de grupo focal en el que participaron los/ las ocho estudiantes restantes.

\subsection{El punto de partida: la revisión de estu- dios en torno al tema}

La decisión de desertar o de permanecer en la educación superior ha sido objeto de estudio desde distintos lugares. De acuerdo con Fernández (2009, 2012), en las investigaciones realizadas en Latinoamérica el concepto más usado ha sido deserción, aunque a partir de los años noventa se popularizaron los términos persistencia y retención. No obstante, las investigaciones realizadas sobre el tema, además de ser escasas, se interesan en analizar las causas de abandono por parte de los universitarios y pocas veces piensan sobre las razones por las cuales se mantienen (Velásquez, 2010).
En términos de deserción, Fernández (2012) y Arias (2013) coinciden en que el modelo explicativo de Vincent Tinto es el más usado; éste sobrepone los factores internos del sujeto y considera que, a mayor adaptación del estudiante a la vida universitaria, mayor será su compromiso y menos la probabilidad de desertar (Fishbein y Ajzen, 1975, citado en Rodríguez, 2019). Empero para Arias (2013), su aplicabilidad es limitada, debido a la foraneidad del modelo y a que diversos estudios realizados en Latinoamérica ${ }^{4}$ (Fernández, 2009) indican que los factores socioeconómicos son las causas más importantes.

Según Rodríguez (2019), entre el año 2006 y 2016 se han dado dos tendencias alrededor del abordaje del fenómeno en Colombia. La primera está relacionada con el desarrollo de investigaciones cuantitativas, que posteriormente serían desplazadas por estudios cualitativos cuyo interés además de conocer la deserción, es develar las acciones que la mitiguen y fomenten su prevención (tendencia en la que se incluye el Ministerio de Educación Nacional de Colombia, 2015b).

Ahora bien, Pineda (2010) plantea que el éxito académico es el resultado de las acciones individuales de los/las estudiantes, sumadas a las estrategias ejecutadas por las instituciones para apoyarlos. Tomando en cuenta lo institucional, el estudio de Fonseca-Grandón (2018) pone de manifiesto que el currículo universitario es un arma de doble filo, pues si bien puede favorecer la permanencia de los/las estudiantes, también puede provocar su deserción.

Por su parte, Fernández, Martínez-Conde y Melipillán (2009) encontraron que el uso de estrategias de aprendizaje complejas y una alta autoestima académica predicen un buen rendimiento académico, factor clave para la permanencia universitaria. Sin embargo, Gore (2010), señala que se trata de un fenómeno multifactorial en el que inciden, además de lo académico, el compromiso institucional y las redes de apoyo.

De otro lado, Espinosa-Castro y Mariño-Castro (2018) señalan que los factores que más inciden son el socioeconómico y el individual, en los que se destacan las dificultades económicas y los asuntos laborales respectiva-

Los estudios a los que se hace referencia son Centro Interamericano para el Desarrollo del Conocimiento en la Formación Profesional (1994); Instituto Internacional de la Unesco para la Educación Superior en América Latina y el Caribe (2005); Muñoz (2004); Zúñiga (2006); Donoso y Schiefelbein (2007); Schwartzman (2004) y Geldstein (2004); y están citados en Fernández (2009). 
mente. Canales y De los Ríos (2009) destacan características personales como la perseverancia, el esfuerzo, la seguridad, la capacidad de reconocer tanto sus límites como sus posibilidades para actuar en consecuencia y la percepción de que obtener un título profesional mejora las condiciones socioeconómicas.

Asimismo, Parada, Correa y Cárdenas (2017) identifican que el factor más influyente es el personal, integrado por la motivación personal, la vocación, el gusto por la carrera elegida; estas autoras también incluyen factores institucionales y académicos, como el currículo, la pedagogía, la interacción con docentes y pares, y los recursos académicos. A nivel personal y familiar, otras variables fueron enfatizadas, tales como: estado civil, actividades extracurriculares, nivel educativo de los padres, género y convivencia o no con la familia de origen (Giovagnoli, 2002).

A nivel local, Flórez (2015) halló que a pesar de que existen aspectos estructurales de gran peso que influyen negativamente sobre el sujeto y que escapan a su control, hay también factores de orden subjetivo/individual que impactan en la decisión de persistir en el proceso educativo, como la convicción por alcanzar un título. Asimismo, la familia aparece como un soporte importante, al igual que algunos aspectos institucionales como la relación del estudiantado con sus docentes y compañeros/as, los estímulos económicos, entre otros.

Finalmente, es importante mencionar que el grupo de investigación Cultura y Desarrollo Humano de la Universidad del Valle, desde una perspectiva del aprendizaje cultural, ha desarrollado proyectos de intervención e investigación relacionados con la deserción. En un estudio sobre capital académico de estudiantes, encontró que "los bajos puntajes [en las Pruebas Saber $11^{5}$ ] están correlacionados con el insuficiente rendimiento académico desde el primer semestre" (Tenorio y Zambrano, 2009, p. 113). Este estudio pone en el centro de la discusión el bajo nivel de capital académico de los jóvenes para enfrentar las exigencias académicas universitarias.

Actualmente esta misma universidad adelanta la estrategia de acompañamiento y se- guimiento estudiantil (ASES) para los/las estudiantes recién ingresados/as pertenecientes a los programas nacionales Ser Pilo Paga, Generación $E^{6} \mathrm{o}$ admitidos por condición de excepción ${ }^{7}$, la cual surgió en 2016 buscando promover el éxito académico (Barbosa, Castillo y Vásquez, 2018). Sobre el impacto de esta estrategia, Escobar (2020) encontró que el rendimiento académico de estudiantes que participaron de ésta fue superior al de aquellos/as que no participaron.

Otra estrategia relevante de esta institución son los Grupos de Apoyo a la Cultura Académica GRACA, los cuales desde 2014 acompañan a estudiantes en aspectos que involucran la lectura y la escritura, con el fin de reducir la deserción temprana (Mora y Rodríguez, 2016).

\subsection{La prueba y los soportes, conceptos cla- ve para acceder a la experiencia de los indi- viduos}

Para el análisis del objeto de estudio se retomaron los conceptos de prueba y soportes, derivados de la sociología del individuo de Danilo Martuccelli (2006), quien propone una vía de análisis que va del individuo, a través de la narrativa de sus experiencias, a la comprensión del trabajo de las estructuras sociales.

Para Martuccelli (2010) existen tres perspectivas para entender los cambios en la contemporaneidad: socialización, subjetivación e individuación. La primera aborda los procesos de construcción psicosociológica de los actores, la interiorización de la norma y cómo, a partir de las disposiciones incorporadas las personas, se convierten en sujetos. La subjetivación explica cómo se da la relación entre movilizaciones, luchas sociales y mecanismos de dominación de un momento histórico y las experiencias personales: "aborda, en el marco de la sociología, el problema de constitución del sujeto como el resultado de una dinámica socio-política de emancipación” (p.79).

Por último, la individuación "se interesa, desde una perspectiva histórica, [por el] tipo de individuo que es estructuralmente fabricado por una sociedad" (Martuccelli, 2010, p.79). En otras palabras, esta alude al proceso por

\footnotetext{
Pruebas de Estado para el ingreso a la educación superior en Colombia.

6 Ser Pilo Paga era un programa del Ministerio de Educación Nacional de Colombia que buscó beneficiar a estudiantes destacados en las Pruebas Saber 11 y de escasos recursos económicos; a través del acceso a universidades acreditadas. Actualmente se desarrolla un programa similar denominado Generación E.

La condición de excepción para la admisión a la Universidad del Valle es una acción afirmativa para poblaciones étnicas o en situación de vulnerabilidad social.
} 
el cual el individuo se construye a sí mismo como sujeto, a partir de enfrentar una serie de pruebas, haciendo uso de los diferentes soportes que corresponden a su trayectoria particular. Martuccelli (2006) se inscribe en esta última perspectiva, la cual permite comprender la constitución de los individuos como actores sociales a través de una serie de pruebas que deben afrontar, desde una lectura de su subjetividad e identidad y no desde las posiciones sociales o habitus de los individuos.

Para este autor la subjetividad se entiende como "la vivencia de poseer un dominio personal sustraído a lo social. Es una experiencia particular de sí mismo; la sensación -validada social y culturalmente- que tenemos 'algo' en nosotros mismos que escapa a lo social” (p. 53). Así, la subjetividad se ubica entre la esfera pública y privada, pues existe siempre y cuando se relacione y se oponga a otras.

La identidad, por su parte, asegura la permanencia de una persona en el tiempo y le permite hacer parte de un conjunto de perfiles socioculturales asociados a colectivos ubicados en un período histórico:

En el núcleo de la noción de identidad [existe] un vínculo particular entre lo personal y lo colectivo $-\mathrm{y}$ es este vínculo que es el meollo del problema-. No hay identidad personal sin presencia de identidades colectivas; $y$ al mismo tiempo, todo perfil identitario colectivo sirve a la estructuración de identidades personales ( $\mathrm{p}$. 47) (Martuccelli, 2006, p. 47).

Es así como las experiencias de los individuos, atravesadas por la identidad y la subjetividad, les permiten asumir pruebas que representan una articulación entre los problemas del individuo y la estructura social; "las pruebas son testimonio de cómo las estructuras actúan y son vividas por los individuos" (Román, 2016, p. 31).

En palabras de Martuccelli (2006) una prueba es "una situación difícil o dolorosa, a la cual estamos confrontados, lo que supone que de una $u$ otra manera exista una percepción particular de ella. No hay prueba sin percepción." (p. 102). A su vez, los individuos perciben que están atravesando momentos difíciles que pueden ser entendidos como tensiones, es decir, manifestaciones de la prueba.

La prueba, en tanto expresión del proceso de selección social, muestra que no todas las personas tienen los mismos recursos para enfren- tarlas; por lo tanto, siempre habrá alguien que, independiente de su posición social, no saldrá bien librado de ésta. Ahora bien, al enfrentar una prueba los individuos hacen uso de soportes -es decir, de un "conjunto heterogéneo de elementos, reales o imaginarios, tejidos a través de relaciones con los demás o consigo mismo" (Martuccelli, 2007, p. 63)- que les ayudan a sostenerse interna y externamente. En este sentido, este modelo de análisis propone entender cómo el individuo se posiciona frente a la sociedad y se construye a sí mismo (Román, 2016).

\subsection{El proceso de formación universitario como prueba y los soportes usados para la permanencia estudiantil}

Para Martuccelli (2006, citado en Román, 2016), una de las pruebas más importantes en la vida de los sujetos es la prueba escolar, en tanto "1) actúa como un proceso de selección social que permite discernir a los exitosos y premiar a aquellos que logren surcar este proceso; 2) otorga un tipo de confianza institucional que da legitimidad a ciertos individuos sobre otros" (p.31).

Quienes surcan el proceso de selección social, experimentan lo que Velásquez define como permanencia estudiantil:

Proceso que vive el estudiante que le permiten ingresar, cursar y culminar su plan de estudios, [...] caracterizándose por el establecimiento de relaciones sociales y afectado por los procesos formativos previos a la universidad, los de ingreso a la misma, su historia académica, su situación socioeconómica, la capacidad de adaptación, la resiliencia y la tolerancia a la frustración (2010, p. 6).

Según Martuccelli (2006), los soportes, en tanto herramientas de naturaleza social, política, económica u otras, son la primera dimensión social del individuo, son su sostén, su uso le permite al individuo proseguir con su vida. "Los soportes pueden describirse como hábitos incorporados y objetivados que facilitan o dificultan que los individuos se relacionen con otros. Estos soportes dependen de la trayectoria del individuo (su historia) y no de la posición del individuo en un grupo específico" (Roman, 2016, p.30).

Martuccelli (2007) define los soportes individuales como aquellas habilidades internas que poseen los sujetos para soportarse a sí 
mismos, algunos de estos son: la autonomía, relacionada con la "capacidad para fijar por sí mismo las orientaciones de su acción" (p.38); la independencia o capacidad para entenderse como parte de una sociedad y ya no de una comunidad; la racionalización, entendida como la capacidad de autocontrol; y la expresión, que se da cuando el individuo es capaz de "manifestarse fuera de él, por sus actos, lo que es en el interior" (p.38).

Los soportes individuales, entonces, "provienen de las habilidades interiores que tienen los individuos para sostenerse en su relación con otras personas" (Román, 2016, p.30). En contraste, los soportes externos son relacionales y dependen de otras personas o instituciones; algunas veces pueden estar, otras veces pueden desaparecer.

Así, los soportes individuales usados por los/las estudiantes en su proceso de formación universitario son aquellos asociados con sus características individuales: habilidades, perseverancia en el alcance de metas, capacidades de reconocer sus límites o posibilidades y actuar en consecuencia con ello, motivaciones personales, vocaciones, métodos de estudio, capitales académicos, historias personales, las expectativas que se hayan trazado, entre otras.

Por su parte, como soportes externos se pueden señalar los aspectos socioeconómicos, familiares e institucionales relacionados con el aporte no solo de las familias, sino también de la universidad para el logro de las metas individuales y grupales tales como el cuerpo docente, la carga e integración académica, becas, servicios estudiantiles, etcétera (Canales y De los Ríos, 2009; Fernández, 2012; Coulon, 1997, citado en Arias, 2013; Cely y Durán, 2014; Franzante, Hernández y Hernández, 2014; Vásquez y Rodríguez, 2007, citados en Cely y Durán, 2014).

Dentro de esta última categoría de soportes externos se ubica lo que hemos denominado en este estudio como estrategias sociales y colectivas que se producen intencionalmente o no en el escenario universitario -relacionadas con la interacción de estudiantes con docentes y pares (Parada, Correa y Cárdenas, 2017), así como con el establecimiento de vínculos y formas de convivencia que fomentan el sentido de pertenencia e integración de los jóvenes con su carrera y la institución (Martinic, 2019). Lo anterior también contribuye a la permanencia estudiantil universitaria, aunque la mayoría de las veces se pasa por alto en los estudios que abordan esta problemática.

De acuerdo con Martuccelli (2006), los soportes permiten que el individuo sea y se sostenga: "es solamente cuando un individuo está activamente sostenido desde el exterior, que el actor tiene la ilusión de poder mantenerse desde el interior. El punto es fundamental. Ningún individuo se sostiene solo" (p. 34). Una vez esbozados los aspectos básicos que constituyeron el modelo de análisis de este estudio, se presentan a continuación los principales resultados y una aproximación analítica de los mismos.

\subsection{Momentos de tensión en la formación académica de Trabajo Social}

Los/las estudiantes reconocieron principalmente tres momentos de mayor tensión durante el proceso de formación académica: el ingreso y adaptación a la universidad, el curso de algunas asignaturas y la práctica académica. El ingreso y adaptación a la universidad fue considerado como una situación tensionante en el proceso de formación académica, debido a los cambios que implica el tránsito entre la educación media y la educación superior, así como por el momento de su ciclo vital individual.

Si bien algunos estudios sobre deserción y permanencia estudiantil mencionan que la educación preliminar y el rendimiento académico del primer año de universidad inciden relevantemente (Valdés y Peláez, 2016; Fonseca-Grandón, 2018; Espinosa-Castro y Mariño-Castro, 2018), esto no se vio reflejado en el caso de los/las estudiantes entrevistados/ as; pues aunque su rendimiento académico en la universidad disminuyó respecto del que tenían en la secundaria -situación atribuida a la procedencia de instituciones educativas con un "bajo nivel académico"- esto no representó una amenaza para su continuidad en el proceso de formación.

A las tensiones vividas durante este primer momento se le suman las crisis que para algunos/as estudiantes representa el paso de la adolescencia a la juventud, justo cuando el individuo, antes adolescente, debe empezar a intimar "con afiliaciones concretas que pueden requerir sacrificios y compromisos significativos" (Erikson, 1982, p. 90), tal y como la realización de una carrera universitaria. En ese sentido, los/las participantes en la investi- 
gación reconocieron que sus "formas de ser y pensar" eran diferentes en ese entonces, producto de idiosincrasias derivadas de contextos menos heterogéneos que la universidad, como la familia, la escuela y la iglesia.

Cuando entré a la universidad se abrió todo (...) la edad, los pensamientos, la sexualidad, el haber venido de un colegio privado y de solamente mujeres (...) porque las lógicas son diferentes (Lina, grupo focal, 03 de octubre de 2017).

De otro lado, también se identificaron tensiones experimentadas durante el curso de algunas asignaturas relacionadas con: la percepción de su calidad académica en función de la exigencia, la existencia de conflictos principalmente de naturaleza política derivados de sus orientaciones teóricas, así como por los niveles de reflexión suscitados a nivel personal en los/las estudiantes.

Frente a esto se encontró que el nivel de exigencia de asignaturas vinculadas especialmente con la investigación social derivó en tensiones, debido a que se abordaban asuntos relacionados con la dimensión epistemológica del conocimiento, que implicaba para las/os entrevistados cierta capacidad de abstracción, así como un ejercicio permanente de escritura más formal del que, afirmaron, estaban acostumbrados/as a realizar:

Estrategias de Investigación me marcó muchísimo, fue el momento en el que empecé a escribir en serio, y reconoci de mí muchas fallas en la escritura (Tamara, estudiante entrevistada el 12 de septiembre de 2017).

Sin embargo, respecto a la exigencia académica también se encontró lo contrario: algunos/as señalaron que la ausencia de exigencia académica de algunas asignaturas no satisfacía las expectativas de aprendizaje significativo, asunto que les desmotivaba para continuar en la carrera:

Me quería salir porque eran unas materias muy básicas y eso hacía que sintiera que estaba perdiendo mi tiempo, [...] no sentía que estuviera aprendiendo (Daniela, grupo focal, $03 \mathrm{de}$ octubre de 2017).
Al respecto, algunos estudios indican que, dentro de los factores personales que inciden en la permanencia estudiantil universitaria, la motivación académica de los/las estudiantes es fundamental (Palmero, 2005, citado en Arias, 2013; Arias y Lopera, 2013; Parada, Correa y Cárdenas, 2017).

La satisfacción estudiantil respecto a la calidad educativa está relacionada con el bienestar experimentado por el estudiantado al sentir atendidas sus expectativas académicas por parte de la institución (Surdez, Sandoval y Lamoyi, 2018), entre las cuales se encuentra un currículo acorde con las necesidades sociales e individuales. En este sentido, es posible que la satisfacción derivada del cumplimento de las expectativas se convierta en un soporte para los/las estudiantes.

Asimismo, se identificó la presencia de conflictos por parte de los/las estudiantes frente a la orientación teórica de algunas asignaturas, que fueron calificadas como conservadoras del orden social y fragmentadoras de la realidad para su conocimiento y abordaje. Estas tensiones revelan que durante el proceso formativo los/las estudiantes van apropiando posturas teóricas de mayor alcance e implicación política.

Con el tema este de la Gerencia Social [...] como que veía que con la carrera no iba a poder buscar una transformación, que no iba a dejar de reproducir lo que ya conocía del orden social (Natalia, entrevistada el 14 de septiembre de 2017).

Además, los hallazgos de este estudio indicaron que la naturaleza de algunos de los contenidos incluidos en las asignaturas ${ }^{8}$ del currículo de formación profesional, interpelaron emocionalmente al estudiantado. Es decir, en la medida que los temas objeto de reflexión en el aula suponen realidades cercanas, generan cuestionamientos sobre las trayectorias de vida de los/las estudiantes y sobre los marcos de referencia socioculturales a partir de los cuales actúan; estas tensiones, que los/las comprometen a nivel emocional, les exigen una mayor tarea autorreflexiva:

Me iba a salir de la carrera sobre todo por Psicopatología, a mí me dio muy duro, porque

Estas asignaturas pertenecen al componente de formación en intervención con familias; como Individuo y Familia I y II; Psicopatología; Muerte y Duelo en Contextos de Violencia. 
empecé a enfrentarme con cosas mías y creo que ese fue un momento decisivo (Daniela, grupo focal, 03 de octubre de 2017).

Por otro lado, se encontró que la práctica académica representó el momento más tensionante del proceso de formación académica universitaria para las/os entrevistados. Diversos aspectos incidieron en ello: los cambios que se dan en el paso de ser estudiante a enfrentarse con el ejercicio profesional, el proceso de selección e inducción a las instituciones de práctica, la puesta en marcha de los aprendizajes obtenidos, los cuestionamientos frente a la profesión, situaciones de la vida personal que los/las estudiantes vivieron simultáneamente, el tiempo que ocupaban los deberes académicos relacionados con la misma y aspectos institucionales particulares de cada centro de práctica, entre otros.

Práctica fue como un momento difícil [...] estuve en crisis, me puse a cuestionarme muchas cosas, acerca de si eso era lo que realmente quería para mi vida y si realmente eso era lo que quería seguir haciendo (Ángela, grupo focal, 03 de octubre de 2020).

La práctica académica significa la salida del espacio académico, desde donde la transformación de la realidad social se idealiza y se va al encuentro del complejo campo de la intervención profesional; se trata de un ejercicio formal y estructurado de intervención social que los/las estudiantes deben asumir con total dedicación y responsabilidad. En este momento se incrementaron los cuestionamientos frente a la elección e intervención profesional; algunos/as estudiantes pensaron en abandonar la carrera, sin embargo, vivir este momento les permitió reafirmar su identidad profesional. Estas interpelaciones sobre la naturaleza y el quehacer de Trabajo Social hacen parte del proceso de construcción de una identidad profesional que vincula construcciones objetivas y subjetivas al respecto, el cual continúa hasta el ejercicio profesional, como lo afirma Blanco (2019).

Por otra parte, el tiempo ocupado por las actividades de la práctica académica, dentro y fuera del centro de práctica, más el tiempo destinado a los deberes de otras asignaturas en curso, constituyeron un factor estresante que afectó la salud física y mental de algunos/ as estudiantes, así como también su situación económica, pues no todas las instituciones les ofrecían una retribución de esta naturaleza, obligando a quienes dependían económicamente de sí mismos/as a buscar otras actividades generadoras de ingresos.

No tenés tiempo para dedicarle a tu misma salud, mental y fisica, hace tiempísimo no salía a trotar porque llegaba cansada a mi casa, [...] llegaba a las 8:00 p.m y decía "Voy a ponerme a leer", mentiras, me quedaba dormida, era un cansancio emocional y mental que solamente llegaba con ganas de descansar (Natasha, entrevistada el 07 de septiembre de 2017).

\subsection{Los soportes utilizados por los/las estu- diantes en el proceso de formación acadé- mica}

Frente a los principales soportes usados por los/las entrevistados/as, los hallazgos muestran la importancia que cobran aspectos subjetivos y relacionales cuando se enfrentan los momentos de tensión en el proceso de formación académica, en tanto prueba estructural. Es así como se identificaron diferentes soportes: cualidades autopercibidas, la familia, la pareja, los/las compañeros/as, acciones de los/las docentes del programa académico, algunas de las iniciativas que la Escuela de Trabajo Social y Desarrollo Humano pone en marcha para con los/las estudiantes, y el Servicio Psicológico de la universidad. Estos elementos harían parte de lo que Martuccelli planteaba como soportes internos y externos (Román, 2016).

Los soportes internos manifestados por los/ las estudiantes integran características propias y rasgos de personalidad que les permitieron afrontar las diferentes tensiones presentadas durante su formación académica. Entre las actitudes, cualidades y características identificadas se encuentran la auto-exigencia, el compromiso, el interés por la profesión y la disposición a realizar actividades para su bienestar individual. Si bien estos soportes podrían existir o no antes de ingresar al programa académico, se compatibilizan con las tensiones que tienen lugar en el proceso de formación académica y por lo tanto sostienen al individuo durante el mismo.

Algunos/as estudiantes logran fortalecer sus capacidades y modificar aspectos individuales que les permiten sobrellevar dificultades durante el proceso formativo, lo que suele ser reconocido por ellos/ellas al finalizar la carrera: 
De mi vida cambiaron muchas cosas desde que entré a estudiar Trabajo Social, he aprendido muchísimo, y me siento en la capacidad de sentarme a conversar con otra persona sobre eso, he tenido mis crisis y mis momentos en que digo que Trabajo Social tiene muchas falencias (...), pero yo quiero ser trabajadora social (Tamara, estudiante entrevistada el 12 de septiembre de 2017).

No obstante, los soportes más relevantes para los/las estudiantes son los externos, aquellos de carácter relacional, en los que la familia, la pareja, amigos/as y los/las compañeras aparecen como apoyos fundamentales. "El soporte social puede ser definido como la existencia o disponibilidad de personas en quienes se puede confiar, personas que se muestran preocupadas con el individuo, que lo valoran y le demuestran aprecio" (Sarason, Levine, Basham y Sarason, 1983, citadas en Baptista, Rigotto, Cardoso y Marín, 2012, p. 3).

Para los/las estudiantes su núcleo familiar representó un recurso fundamental no sólo al afrontar los momentos tensionantes, sino también durante toda la formación académica, puesto que además de compañía, brindaron apoyo emocional y económico, aspectos indispensables durante la carrera:

El apoyo de la familia indiscutiblemente... creo que también son un buen refugio, son un soporte emocional, económico, social, bien o mal están allí (Verónica, entrevistada el 11 de septiembre de 2017).

Que ellos/as asuman a sus familias como un soporte en la formación académica permite ver que, aunque ésta contribuya a una mayor independencia y autonomía, no significa que el núcleo familiar no tenga influencia en su proceso de formación. Además, los contenidos teóricos asociados a las familias pueden influir en cómo ellos/ellas perciben a sus familias y el lugar que les otorgan en sus vidas.

Por otra parte, la pareja de algunos/as entrevistados/as fue reconocida como un soporte en los momentos difíciles; su apoyo y compañía les permitió enfrentar de mejor manera algunas tensiones:

El apoyo de mi pareja fue crucial, porque [él] ya había transitado por esto de hacer un trabajo de grado, de enfrentarse a las tensiones de la vida académica, [...] en cierta manera se convertía en un soporte (Verónica, estudiante entrevistada el 11 de septiembre de 2017).

Adicional a los soportes externos ya mencionados, los/las compañeras de carrera constituyen el principal soporte relacional de los/ las estudiantes, pues aunque los significados otorgados a los momentos difíciles sean diferentes, las experiencias compartidas como pares fueron similares y facilitaron afrontar dichas dificultades en conjunto:

Uno se hablaba con compañeros y encontraba en el discurso del otro una situación propia, eso ayudaba a que uno sintiera que no sólo le estaba pasando a uno, entonces como que era el apoyo ahí implícito (Daniela, grupo focal, 03 octubre 2017).

Este respaldo entre compañeros/as puede relacionarse con un proceso de identificación entre sí que los ubica como pares no sólo por ser estudiantes sino también por su origen social. Al respecto, Bourdieu y Passeron (2003) plantean que los/las estudiantes universitarios/ as poseen dos identidades, una proclamada por sí mismos/as y una oculta: la primera se da a partir de sus prácticas y experiencias comunes en la universidad que los ubica en la condición de estudiantes; la segunda a partir de las condiciones de existencia de su origen social, sus capitales social, económico y cultural.

En este sentido, Román (2016) encontró que para becarios/as de una universidad privada en Perú, uno de sus soportes lo constituyen otros participantes del mismo programa estatal del que formaban parte, sobre todo porque compartían una misma posición social de origen y capitales similares que los diferenciaba del resto de estudiantes, quienes solían discriminarlos.

Lo expresado por los/las estudiantes frente a estos soportes evidenció no sólo la importancia que para ellos/las tienen las relaciones interpersonales, sino también su capacidad de reflexión sobre éstas, lo que puede estar relacionado con que a lo largo de su proceso académico éstas fueron objeto de reflexión. Asimismo, se encontró que las situaciones difíciles afectaron sus relaciones interpersonales; es decir, que los sentimientos derivados de los momentos tensionantes pudieron impactar transitoriamente las relaciones que son asumidas como soportes, a través de discusiones, 
conflictos, entre otros. Esto permite concluir que las tensiones y los soportes no sostienen una relación lineal: a pesar de que los soportes son necesarios para enfrentar y superar las pruebas, estas también los afectan y por ende a los individuos, puesto que alteran la sensación de suspensión social (Martuccelli, 2006).

\subsection{Soportes institucionales}

Actualmente, en Colombia han aumentado los esfuerzos de las instituciones de Educación superior (IES) por promover la permanencia estudiantil a partir de estrategias para prevenir la deserción, esto gracias a que desde el 2015, a través de los lineamientos de acreditación institucional, el Ministerio de Educación Nacional (MEN) convoca a las instituciones de Educación superior a fortalecer su capacidad para desarrollar y ejecutar políticas y programas que fomenten la permanencia y graduación estudiantil (MEN, 2015a). Para el caso de la universidad en cuestión, se han implementado diversas estrategias formales de retención y de consejería estudiantil para prevenir la deserción y aumentar la permanencia y graduación.

En este sentido, de los soportes institucionales no sólo se identificaron estrategias planificadas del programa académico o la universidad, sino también algunas acciones individuales de miembros de la institución que fueron reconocidas por los/las estudiantes como soportes institucionales. El principal aspecto institucional identificado como un apoyo proviene de las acciones de los/las docentes, de su disposición y diligencia frente a situaciones académicas y personales de los/las estudiantes, quienes lo resaltaron como una particularidad del programa académico de Trabajo Social que en otras facultades de la universidad es difícil encontrar.

Hay algunos docentes que se acercan desde una postura muy personal, desde la empatía que se construya, (...) te preguntan cómo vas, pero creo que es más por su iniciativa que por algo que quiera hacer el programa académico (Jersson, entrevistado el 13 de septiembre de 2017).
Según Artavia (2005), los profesionales de la educación tienen la posibilidad de reflexionar y elegir ser flexibles en el desempeño de su labor, lo que les permite una mayor interacción con los/las estudiantes y construir relaciones impregnadas de mayor afecto, seguridad y comprensión hacia ellos/ellas. Esto está relacionado con la interpretación que hace cada docente del acto educativo, pues se observa que, "más allá de una transmisión teórica o de un saber específico, existe un encuentro afectivo y humano donde sus protagonistas confluyen con sus expectativas y limitaciones" (Vásquez, 2005, p. 4).

Con relación al apoyo brindado por el programa de Trabajo Social, los/las estudiantes expresaron la necesidad de mayor acompañamiento ante las situaciones tensionantes de la formación; sin embargo, reconocieron que iniciativas como los talleres de transición emocional, dirigidos a los estudiantes en práctica, constituyeron un soporte durante este momento?.

En relación con los soportes brindados por la universidad, se reconoció el Servicio Psicológico, el cual brinda atención a los/las estudiantes. Sin embargo, dicha atención no cumplió totalmente con sus expectativas. También se identificó el recurso a espacios extracurriculares de carácter cultural y deportivo, agenciados por Bienestar Universitario. Esto evidencia que todos los sujetos cuentan con soportes y los necesitan para enfrentar las pruebas. Sin embargo, no todos tienen la misma legitimidad, y lo que puede ser un soporte para una persona, puede no serlo para otra (Martuccelli, 2006).

\section{Conclusiones}

Finalmente, este estudio identificó que los principales momentos de tensión vividos por los/las estudiantes de Trabajo Social, durante el proceso de formación académica, fueron el ingreso y adaptación a la universidad, el curso de algunas asignaturas y la práctica académica. Estos momentos no se limitan a aspectos curriculares o académicos, están atravesados por las trayectorias individuales de los/las estudiantes y son manifestaciones de lo que Martuccelli (2006) ha definido como prueba: una

\footnotetext{
El programa académico de Trabajo Social actualmente desarrolla el Programa de Consejería Estudiantil (Universidad del Valle; 2005) como parte de la actividad académica de los/las profesoras de carrera para apoyar el proceso formativo de los/las estudiantes.
} 
situación difícil o dolorosa que los individuos deben enfrentar, proceso en el cual interfieren sus subjetividades.

Estos momentos representan, en términos de este autor, una prueba estructural, en tanto es común a todos los miembros de un colectivo -en este caso a los/las estudiantes-, sin embargo, se vive desde posiciones y experiencias disímiles. Si bien estas tensiones generaron algunos cuestionamientos en los/las estudiantes frente a su elección profesional, no siempre suscitaron intenciones de abandonar la carrera; por el contrario, significaron reforzar su propósito de ser profesional.

Por otro lado, los soportes que permitieron a los/las estudiantes afrontar los mo- mentos de mayor tensión en el proceso de formación académica fueron principalmente aspectos externos de carácter institucional como las relaciones con sus compañeros de estudio y docentes- y relacionados con la familia y la pareja. Es importante precisar que a pesar de que los soportes identificados fueron diversos, estuvieron asociados a aspectos subjetivos y relacionales, principalmente al acompañamiento de sus pares y al vínculo construido con los/las docentes, primando sobre aspectos económicos o académicos, los cuales han sido señalados por otras investigaciones como determinantes en la decisión de permanecer o desertar de la formación universitaria.

\section{Referencias bibliográficas}

Arias, M.I. (2013). La permanencia estudiantil universitaria abordada desde lo psicológico y lo educativo. Colombia: Universidad de Manizales.

Arias, M.I., y Lopera, W. (2013). Estudio comparativo de los factores relacionados con la permanencia estudiantil universitaria en psicología de la Fundación Universitaria Luis Amigó, Medellín (tesis de maestría). Convenio Universidad de Manizales y CINDE, Manizales, Colombia. Recuperado de: http:// ridum.umanizales.edu.co:8080/xmlui/bitstream/handle/6789/820/ESTUDIO $\% 20$ ?sequence $=1$

Artavia, J. M. (2005). Interacciones personales entre docentes y estudiantes en el proceso de enseñanza y aprendizaje. Revista electrónica actualidades investigativas en educación, 5(2), 1-19. Doi: 10.15517/ AIE.V5I2.9142

Baptista, M.N., Risotto, D.M., Cardoso, H. y Marín, F. (2012). Soporte social, familiar y autoconcepto. Psicología desde el Caribe, 29(1), 1-18. Recuperado de: https://www.redalyc.org/pdf/213/21323171002. pdf

Barbosa, F.A., Castillo, N.S. y Vásquez, M.L. (2018). Estrategia de Acompañamiento y Seguimiento Estudiantil en la Universidad del Valle (Colombia). Recuperado de: https://ridda2.utp.ac.pa/handle/123456789/5642

Blanco, M.D.P. (2019). Sociología de la experiencia y reconstrucción de identidades profesionales: una mirada al Trabajo Social. Revista Palobra, 19(1), 5-21. Recuperado de: https://core.ac.uk/reader/287298074

Bourdieu, P. y Passeron J.C. (2003). Los herederos: los estudiantes y la cultura. Argentina: Siglo XXI Editores.

Canales, A. y De los Ríos, D. (2009). Entendiendo la permanencia de estudiantes vulnerables en el sistema universitario (1-38). Chile: Universidad de Santiago de Chile. Recuperado de: https://www.researchgate.net/

Cely, D. y Durán, M. (2014). Causas asociadas a la deserción estudiantil y estrategias de acompañamiento para la permanencia estudiantil. (IV Conferencia Latinoamericana sobre el abandono en la Educación Superior. Medellín, Colombia). Recuperado de: https://revistas.utp.ac.pa/index.php/clabes/article/ view/1732

Erikson, E. (1982). El ciclo vital completado. Madrid, España: Paidós.

Escobar, J.H. (2020). Impacto de la estrategia de Acompañamiento y Seguimiento Estudiantil ASES en el rendimiento académico de los estudiantes de Ser Pilo Paga en la Universidad del Valle: una estimación por propensity score matching. Congresos CLABES, 556-565. Recuperado de https://revistas.utp.ac.pa/ index.php/clabes/article/view/2735

Espinosa-Castro, J. F. y Mariño-Castro, L. M. (2018). Estrategias para la permanencia estudiantil universitaria. Barranquilla, Colombia: Ediciones Universidad Simón Bolívar. Recuperado de: http://bonga. unisimon.edu.co/handle/20.500.12442/2330 
Fernández, O.M., Martínez-Conde, M. y Melipillán, R. (2009). Estrategias de aprendizaje y autoestima: su relación con la permanencia y deserción universitaria. Estudios pedagógicos 35(1), 27-45. Doi: https:// dx.doi.org/10.4067/S0718-07052009000100002

Fernández, N. (2009). Retención y persistencia estudiantil en Instituciones de Educación Superior: una revisión de la literatura. Paradigma, 30(2), 39-61. Recuperado de: http://revistaparadigma.online/ojs/ index.php/paradigma/article/view/436/433

Fernández, N. (2010). Factores asociados con la intención de retiro del trimestre según estudiantes de las carreras largas de la Universidad Simón Bolívar, sede sartenejas. Paradigma, 31(2), 123-150. Recuperado de: http://revistaparadigma.online/ojs/index.php/paradigma/article/view/465/462

Fernández, N. (2012). Retención y persistencia estudiantil en Instituciones de Educación Superior: Una aproximación interdisciplinaria al concepto. Paradigma, 33(2), 63-88. Recuperado de: http://revistaparadigma.online/ojs/index.php/paradigma/article/view/500/497

Flórez, M.A. (2015). Aspectos que inciden en la deserción y en la persistencia de los estudiantes del programa académico de Trabajo Social de la Universidad del Valle Sede Zarzal. (Tesis de pregrado, Universidad del Valle, Zarzal, Colombia).

Fonseca-Grandón, G. (2018). Trayectorias de permanencia y abandono de estudios universitarios: una aproximación desde el currículum y otras variables predictoras. Educación y educadores, 21(2), 239256. Recuperado de: $\mathrm{https}$ ://dialnet.unirioja.es/servlet/articulo?codigo $=6718916$

Franzante, B., Hernández, Y. y Hernández, Y. (2014). Permanencia estudiantil en el contexto universitario actual. Reto pedagógico para la igualdad de oportunidades educativas. Congreso Universidad, 3(2), 1-9. Recuperado de: http://revista.congresouniversidad.cu/index.php/rcu/article/view/604

Giovagnoli, I. (2002). Determinantes de la deserción y graduación universitaria: Una aplicación utilizando modelos de duración (tesis doctoral), Universidad Nacional de La Plata, Argentina). Recuperado de: http://sedici.unlp.edu.ar/handle/10915/3436

Gore, J.N. (2010). The Importance of Freshman Experiences in Predicting Students' Retention Decisions. (Tesis de maestría, Appalachian State University, Boone, NC, EE:UU.). Recuperado de: https://libres. uncg.edu/ir/asu/f/Gore\%20Jessica_2010_Thesis.pdf

Martinic, R. (2019). ¿Qué hay tras la permanencia universitaria? Los cambios más significativos en el acompañamiento académico. Revista: Educação e Pesquisa, Sao Paulo, (45), 1-20. Doi: https://doi. org/10.1590/s1678-4634201945190724

Martuccelli, D. (2006). Lecciones de Sociología del Individuo. Curso del Departamento de Ciencias Sociales, Lima, Perú: Pontificia Universidad Católica del Perú. Recuperado de: http://departamento.pucp. edu.pe/ciencias-sociales/files/2012/06/Martuccelli-Lecciones_de_sociologia_del_individuo2.pdf

Martuccelli, D. (2007). Gramáticas del Individuo. Buenos Aires: Editorial Losada.

Martuccelli, D. (2010) La individuación como macrosociología de la sociedad singularista. Persona y Sociedad. 24(3), 9-29. Recuperado de: https://personaysociedad.uahurtado.cl/index.php/ps/article/view/196

Ministerio de Educación Nacional. (2015a). Estrategias para la permanencia en educación superior: experiencias significativas. Recuperado de: https://www.mineducacion.gov.co/1759/articles-356276_recurso.pdf

Ministerio de Educación Nacional. (2015b). Guía para la implementación del modelo de permanencia y graduación estudiantil en Instituciones de Educación Superior. Recuperado de: https://www.mineducacion.gov.co/1759/articles-356272_recurso.pdf

Mora Cortés, L. y Rodríguez Campo, A. (2016). Metodología para la conformación de los Grupos de Apoyo a la Cultura Académica como estrategia para disminuir el abandono y favorecer el éxito estudiantil. Congresos CLABES. Recuperado de: https://revistas.utp.ac.pa/index.php/clabes/article/view/1367

Parada, D.A., Correa, L. y Cárdenas, Y. (2017). Factores relacionados con la permanencia estudiantil en programas de pregrado de una universidad pública. Investigación en Enfermería: Imagen y Desarrollo, 19(1), 155-170. DOI: https://doi.org/10.11144/Javeriana.ie19-1.frpe

Pineda, C. (2010). Persistencia y Graduación. Hacia un modelo de retención estudiantil para Instituciones de Educación Superior en Colombia. (Tesis de maestría, Universidad de La Sabana, Colombia). Recuperado de: https://intellectum.unisabana.edu.co/bitstream/handle/10818/2532/125341.pdf?sequence=1

Rodríguez, M. (2019). La investigación sobre la deserción universitaria en Colombia 2006-2016. Tendencias y Resultados. Pedagogía y Saberes, (51), 49-66. Universidad Pedagógica Nacional. Facultad de Educación. Recuperado de: http://www.scielo.org.co/pdf/pys/n51/0121-2494-pys-51-49.pdf 
Román, A.M. (2016). Trayendo de vuelta al individuo: los soportes externos en el proceso de inserción y permanencia en la educación superior de los becarios y becarias de Beca 18. (Tesis de maestría, Pontificia Universidad Católica del Perú, Lima, Perú). Recuperado de: http://tesis.pucp.edu.pe/repositorio/ handle/20.500.12404/7277

Surdez, E.G., Sandoval, M. y Lamoyi, C. (2018). Satisfacción estudiantil en la valoración de la calidad educativa universitaria. Educación y Educadores, 21(1), 9-26.

Tenorio, M.C. y Zambrano L.V. (2009). Capital académico de estudiantes que ingresan con puntajes altos, medios y bajos en las pruebas ICFES (Informe final analítico). Proyecto Universidad y Culturas. Universidad del Valle.

Universidad del Valle. (2005). Resolución Consejo Académico $N^{\circ} 078$ junio 9 de 2005. Recuperado de: http://proxse16.univalle.edu.co/ secretariageneral/consejo-academico/resoluciones/ 2005/ CA-078. pdf

Valdés, C. y Peláez, R. (2016). Deserción/permanencia escolar: comprensiones vinculares entre la educación superior y la educación preliminar. Revista de Investigaciones· UCM, 16 (1), 166-176. Doi: http:// dx.doi.org/10.5294/edu.2018.21.1.1

Vásquez, J. (2005). El vínculo docente-alumno y su relación con la deserción. En: Programa Acompañamiento Formativo a Estudiantes de Educación Media en el Proceso de Elección de Estudios Superiores, MEN - UDEA, Colombia. Recuperado de: http://aprendeenlinea.udea.edu.co/lms/men_udea/pluginfile. php/29970/mod_resource/content/0/modulo_5/pdfs/mod05_doc01_vinculo.pdf

Velásquez, C. (2010). La permanencia académica en estudiantes universitarios (artículo inédito). Medellín, Colombia. Recuperado de: https://nanopdf.com/download/articuloderevisionbibliograficasobrepermanencia_pdf

\section{Anexo 1. Instrumento de las entrevistas semiestructuradas}

Investigación: Momentos del proceso de formación académica en Trabajo Social de la Universidad del Valle que generan mayores tensiones en los estudiantes, y los soportes utilizados por ellos para permanecer en el programa académico

Código del proyecto: 01

Código de la entrevista: E01

Entrevista semi-estructurada

Entrevistadoras:

Fecha:

Lugar:

Objetivos de la investigación:

General:

Comprender los momentos del proceso de formación académica en Trabajo Social de la Universidad del Valle que generan mayores tensiones en los y las estudiantes, y los soportes utilizados por ellos para permanecer en el programa académico.

\section{Específicos:}

- Identificar los momentos del proceso de formación académica en Trabajo Social que generan mayor tensión en los y las estudiantes del programa académico.

- Indagar acerca de las expectativas que los y las estudiantes han construido sobre los momentos que les han generado mayores tensiones a lo largo del proceso de formación académica en Trabajo Social de la Universidad del Valle y las insatisfacciones vivenciadas frente a estos.

- Identificar los soportes personales e institucionales que permitieron a los estudiantes afrontar los momentos de mayor tensión en el proceso de formación académica en Trabajo Social de la Universidad.

Objetivo de la entrevista: Comprender las categorías de análisis de esta investigación, a partir de la narración de las/os estudiantes de Trabajo Social de la Universidad del Valle sobre momentos del proceso de formación académica que les generan mayores tensiones y los soportes utilizados por ellos para permanecer en el programa académico.

Encuadre: Se realizarán acuerdos en relación con el tiempo disponible para el desarrollo de la entrevista, la confidencialidad de la información, y el registro de la misma a través de grabaciones.

Caracterización de los sujetos:

\begin{tabular}{|l|l|}
\hline Nombre: & Edad: \\
\hline Género: & Cohorte: \\
\hline
\end{tabular}


1. ¿Cuáles fueron para usted los principales momentos en el proceso de formación académica en Trabajo Social?

2. En estos momentos importantes del proceso de formación académica, ¿qué situaciones difíciles vivió?

3. ¿Qué expectativas tenía para cada uno de esos momentos?, ¿qué esperaba lograr?

4. ¿Qué expectativas se cumplieron o qué expectativas se están cumpliendo actualmente?

5. ¿Por qué consideraba posible que estas expectativas se cumplieran? o ¿por qué considera que es posible que estas expectativas se cumplan?

6. Finalmente, ¿qué permitió que esas expectativas se cumplieran o se estén cumpliendo?

7. ¿Qué correspondencia hubo entre lo que usted esperaba y lo que sucedió o lo que está sucediendo actualmente?

8. ¿Qué expectativas no se cumplieron?

9. A pesar de que no se cumplieron, ¿por qué consideraba que era posible que se cumplieran?

10.¿Qué no permitió que se cumplieran?

11. ¿Qué significaron para usted, aquellas expectativas que no se cumplieron?

12. ¿Considera usted que estas expectativas no cumplidas hicieron que estas situaciones representaran una dificultad para usted?

13. ¿Qué otros aspectos o circunstancias hicieron que estas situaciones representaran una dificultad para usted?

14. ¿Qué emociones le generaron dichas situaciones difíciles o ese no cumplimiento de las expectativas?

15.¿Qué pensó ante estas situaciones?

16.¿Qué hizo para enfrentar dichos momentos?

17.¿Qué aspectos o recursos personales considera le permitieron enfrentar los momentos de tensión en el proceso de formación académica?

18. ¿Considera usted que la institución le ofreció apoyo para enfrentar cada uno de estos momentos? ¿Cómo y a través de qué recursos lo hizo?

19. ¿Hubo otros aspectos o recursos que le permitieran enfrentar dichos momentos?

20.¿Qué aprendizajes obtuvo a partir de estos momentos de tensión que vivió?

21. ¿Desea agregar algo más?

22. Agradecimiento y cierre.

\section{Anexo 2. Instrumento del grupo focal}

Investigación: Momentos del proceso de formación académica en Trabajo Social de la Universidad del Valle que generan mayores tensiones en los estudiantes, y los soportes utilizados por ellos para permanecer en el programa académico

Código del proyecto: 01

Código del grupo focal: G01

Instrumento para grupo focal

Objetivo general de la investigación: Comprender los momentos del proceso de formación académica en Trabajo Social de la Universidad del Valle que generan mayores tensiones en los y las estudiantes, y los soportes utilizados por ellos para permanecer en el programa académico.

\section{Objetivos específicos de la investigación:}

- Identificar los momentos del proceso de formación académica en Trabajo Social que generan mayor tensión en los y las estudiantes del programa académico.

- Indagar acerca de las expectativas que los y las estudiantes han construido sobre los momentos que les han generado mayores tensiones a lo largo del proceso de formación académica en Trabajo Social de la Universidad del Valle y las insatisfacciones vivenciadas frente a estos.

- Identificar los soportes personales e institucionales que permitieron a los estudiantes afrontar los momentos de mayor tensión en el proceso de formación académica en Trabajo Social de la Universidad.

Fecha:

Lugar:

Participantes:

Momentos:

1. Presentación de las investigadoras y presentación del tema.

2. Realización de acuerdos con el grupo.

3. Actividad rompe-hielo: Se pedirá que cada estudiante cuente a los demás una pequeña anécdota acerca del momento más vergonzoso o gracioso que haya vivido en la universidad.

4. Desarrollo de los ejes temáticos.

5. Cierre del grupo focal y agradecimientos.

6. Refrigerio. 
Objetivo grupo focal: Comprender los momentos del proceso de formación académica en
Trabajo Social que generan mayor tensión en los y las estudiantes del programa académico.

Ejes temáticos

- Momentos principales de la formación académica en Trabajo Social

- Expectativas sobre cada momento de la formación académica

- Situaciones difíciles a lo largo de la formación académica en Trabajo Social

- Aspectos o circunstancias que hicieron difíciles estas situaciones

- Emociones generadas a partir de estas situaciones

- Acciones realizadas ante estas situaciones difíciles 